\title{
Salmonella typhimurium A1-R Exquisitely Targets and Arrests a Matrix-producing Triple-negative Breast Carcinoma in a PDOX Model
}

\author{
KAZUYUKI HAMADA ${ }^{1,2,3}$, YUSUKE AOKI ${ }^{1,2}$, JUN YAMAMOTO ${ }^{1,2}$, \\ CHIHIRO HOZUMI ${ }^{4}$, MING ZHAO ${ }^{1}$, TAKUYA MURATA ${ }^{5}$, NORIHIKO SUGISAWA ${ }^{1,2}$, \\ MICHAEL BOUVET ${ }^{2}$, TAKUYA TSUNODA ${ }^{3}$ and ROBERT M. HOFFMAN ${ }^{1,2}$ \\ ${ }^{1}$ AntiCancer Inc, San Diego, CA, U.S.A.; \\ ${ }^{2}$ Department of Surgery, University of California, San Diego, CA, U.S.A.; \\ ${ }^{3}$ Division of Medical Oncology, Department of Medicine, Showa University School of Medicine, Tokyo, Japan; \\ ${ }^{4}$ AntiCancer Japan Inc, Narita, Japan; \\ ${ }^{5}$ Department of Obstetrics and Gynecology 2, Kawasaki Medical School, Okayama, Japan
}

\begin{abstract}
Background/Aim: Triple-negative matrix-producing breast carcinoma $(M P B C)$ is rare, recalcitrant, and highly aggressive. The present study aimed to determine the efficacy of tumor-targeting leucine-arginine auxotroph Salmonella typhimurium ( $S$. typhimurium) Al-R on a triple-negative $M P B C$ in a patient-derived orthotopic xenograft (PDOX) model. Materials and Methods: The PDOX MPBC model was established in the left second mammary gland of nude mice by surgical orthotopic implantation (SOI). PDOX models were randomized into two groups when the tumor volume reached over $70 \mathrm{~mm}^{3}$ : a control group (n=6); and a tumor-targeting $S$. typhimurium Al-R group ( $n=7)$, [intravenous (i.v.) injection of $S$. typhimurium Al-R via the tail vein, weekly, for two weeks]. All mice were sacrificed on day 14. Tumor volume and body weight were measured once per week. Results: S. typhimurium Al-R exquisitely targeted and arrested the growth of the MPBC PDOX compared to the control group ( $p=0.017)$. Conclusion: $S$. typhimurium Al-R has future clinical potential for triplenegative MPBC patients.
\end{abstract}

This article is freely accessible online.

Correspondence to: Robert M. Hoffman, Ph.D., AntiCancer Inc, 7917 Ostrow St, San Diego, CA, 92111, U.S.A. Tel: +1 8586542555, Fax: +18582684175, e-mail: all@anticancer.com; Takuya Tsunoda, MD, Ph.D., Division of Medical Oncology, Department of Medicine, Showa University School of Medicine, Tokyo, Japan. Tel: +81 337848661, Fax: +81 337848661, e-mail: ttsunoda@med.showa-u.ac.jp

Key Words: PDOX, patient-derived orthotopic xenograft, triplenegative breast cancer, matrix-producing breast carcinoma, Salmonella typhimurium A1-R, tumor targeting, efficacy.
Triple-negative matrix-producing breast carcinoma (MPBC) is defined by the absence of estrogen receptor (ER), progesterone receptor $(\mathrm{PgR})$, and human epidermal growth factor receptor 2 (HER2) and the production of a cartilaginous or osseous matrix $(1,2)$. Effective therapy for triple-negative MPBC has not been established due to its rarity (3).

Our laboratory pioneered the patient-derived orthotopic xenograft (PDOX) model 30 years ago by establishing the technique of surgical orthotopic implantation (SOI) $(4,5)$. We have shown that the PDOX model retains the histopathological/molecular and metastatic characteristics of the original tumor after SOI unlike the subcutaneous PDX mouse model (5-7). We previously showed eribulin regressed triple-negative MPBC in PDOX mouse models $(8,9)$.

Leucine-arginine auxotroph Salmonella typhimurium $(S$. typhimurium) A1-R, expressing green fluorescent protein (GFP), accurately targets tumors and does not grow well in normal tissue due to its leucine-arginine auxotrophy (10-12). S. typhimurium A1-R inhibited prostate $(10,12)$, breast (11, $13,14)$, lung $(15,16)$, pancreatic $(17-19)$, ovarian $(20,21)$, stomach (22), and cervical cancer (23), as well as sarcoma (24-26), melanoma (27), and glioma (28).

In the present report we demonstrate that S. typhimurium A1-R exquisitely targets and arrests a triple-negative MPBC in a PDOX mouse model.

\section{Materials and Methods}

Mouse studies. Ethical approval was obtained from the ethics committee of the AntiCancer Institutional Animal Care and Use Committee under the National Institutes of Health Guide Assurance Number A3873-1(8). All experiments were conducted in compliance with Animal Research: Reporting of In Vivo Experiments (ARRIVE) guidelines 2.0. 
Patient tumor. The patient tumor was provided as a discarded pathology specimen by Kawasaki Medical School, Japan, following Research Ethics Committee of Kawasaki Medical School and Hospital approval. All experiments were carried out in accordance with the Declaration of Helsinki and regulations for human studies, and informed consent was obtained from the patient. The patient MPBC tumor was previously established to grow subcutaneously in nude mice. Subcutaneously-grown tumor was harvested and minced into $3 \mathrm{~mm}^{3}$ fragments and orthotopically implanted into the $2 \mathrm{nd} \mathrm{left}$ mammary gland of nude mice as previously described (8).

Preparation of Salmonella typhimurium A1-R. S. typhimurium A1R-GFP (AntiCancer, Inc., San Diego, CA, USA) was produced as described in our previous publications (10-28): Bacteria were incubated in Luria-Bertani (LB) medium containing ampicillin at $37^{\circ} \mathrm{C}$ overnight with shaking. The bacteria were then diluted 10 -fold in LB medium containing ampicillin and incubated for 3 hours under the same conditions. Bacteria were washed with phosphatebuffered saline (PBS), suspended in PBS, and injected into nude mice via the tail vein.

Treatment protocol for the triple-negative MPBC PDOX model. The detailed experimental schema is shown in Figure 1. The triplenegative MPBC PDOX models were randomized into two groups when the tumor volume was over $70 \mathrm{~mm}^{3}$ : Control: untreated control mice; A1-R: S. typhimurium A1-R-GFP treated mice $[i . v$., $5 \times 10^{7}$ colony-forming units (CFU) $S$. typhimurium A1-R -GFP in $100 \mu \mathrm{l}$ PBS (weekly, two weeks)]. Each group comprised six and seven mice, respectively. Tumor size and body weight were measured once a week. Tumor volume was calculated using the following formula: tumor volume $(\mathrm{mm})=$ length $(\mathrm{mm}) \times$ width $(\mathrm{mm})$ $\times$ width $(\mathrm{mm}) \times 1 / 2$. All mice were sacrificed on day 14 .

Fluorescence imaging of S. typhimurium A1-R-GFP in the triplenegative $M P B C P D O X$. Fluorescence images were obtained and analyzed using the UVP ChemStudio (Analytik Jena, Thuringia, Germany).

Statistical analysis. GraphPad Prism 8.4.3 (GraphPad Software, Inc., San Diego, CA, USA) was used for statistical calculations. The Student's $t$-test was used to compare groups. Data are the mean values \pm SD. $p \leq 0.05$ is defined as statistically significant.

\section{Results}

Exquisite targeting of the triple-negative $M P B C P D O X$ by $S$. typhimurium A1-R-GFP. Twenty-four hours after infection of triple-negative MPBC PDOX with S.typhimurium A1-R -GFP, the bacteria selectively targeted the tumor, as demonstrated by GFP fluorescence in the tumor but not in the liver or spleen of the triple-negative MPBC PDOX mouse model (Figure 2).

Efficacy of S. typhimurium Al-R - GFP on the triple-negative $M P B C P D O X$. S. typhimurium A1-R arrested the growth of the triple-negative MPBC $(p=0.017)$. The final tumor volume was obtained on treatment-day 14. Average tumor volume of the control group was $205 \pm 70 \mathrm{~mm}^{3}$ and in the $S$. typhimurium A1-R -GFP group $112 \pm 37 \mathrm{~mm}^{3}$ (Figure 3).

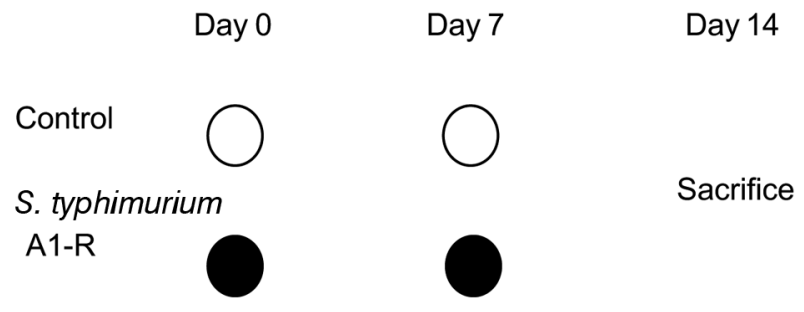

Figure 1. Experimental schema. S. typhimurium Al-R-GFP was injected into the tail vein of triple-negative matrix-producing breast carcinoma PDOX nude mice $\left[5 \times 10^{7}\right.$ colony-forming units (CFU) per $100 \mu \mathrm{l}$ of PBS].

No effect of S. typhimurium A1-R-GFP on body weight of the triple-negative MPBC PDOX mouse model. To determine whether S. typhimurium Al-GFP had a gross adverse effect, the mouse body weight was measured at pre-treatment and post-treatment. The final body weight on treatment-day 14 was $24.7 \pm 0.9 \mathrm{~g}$ for the control group and $24.1 \pm 3.1 \mathrm{~g}$ for the S. typhimurium A1-R - GFP group. There were no significant differences in the body weight between the two groups on day14 ( $p=0.73$ ) (Figure 4), which suggests that $S$. typhimurium A1- R-GFP had no obvious side effects.

\section{Discussion}

In the present study, S. typhimurium A1-R-GFP accurately targeted the triple-negative MPBC in a PDOX model and arrested its growth.

Kusafuka et al. reported the frequency of MPBCs is only $0.2 \%$ of all breast cancers (2). MPBC is usually triplenegative breast cancer (TNBC) and has a high proliferative activity, indicated by high histological grade, high Ki-67 index, and high level of p53 expression $(1,29)$. Shimada et al. reported that the mean Ki-67 index of non-TNBC MPBCs (45\%) was higher than that of TNBCs (36\%) (3).

Due to its rarity, there are only a few clinical trials for MPBC and they showed poor efficacy $(3,30,31)$. Therefore, novel effective therapy is urgently needed for MPBC patients. Our previous studies of triple-negative MPBC and common triple-negative breast cancer (TNBC) PDOX mouse models showed eribulin was effective $(8,9)$.

Bacterial therapy has gained popularity as a cancer immunotherapy in recent years (32). Salmonella, Clostridium, and other bacterial genera have been shown to control tumor growth and promote survival in animal models (32). S. typhimurium A1-R is an auxotrophic leucine-arginine facultative-anaerobic $S$. typhimurium strain, which selectively targets and proliferates in tumors of all types due to, at least in part, its nutritional needs, which appear to be satisfied in 


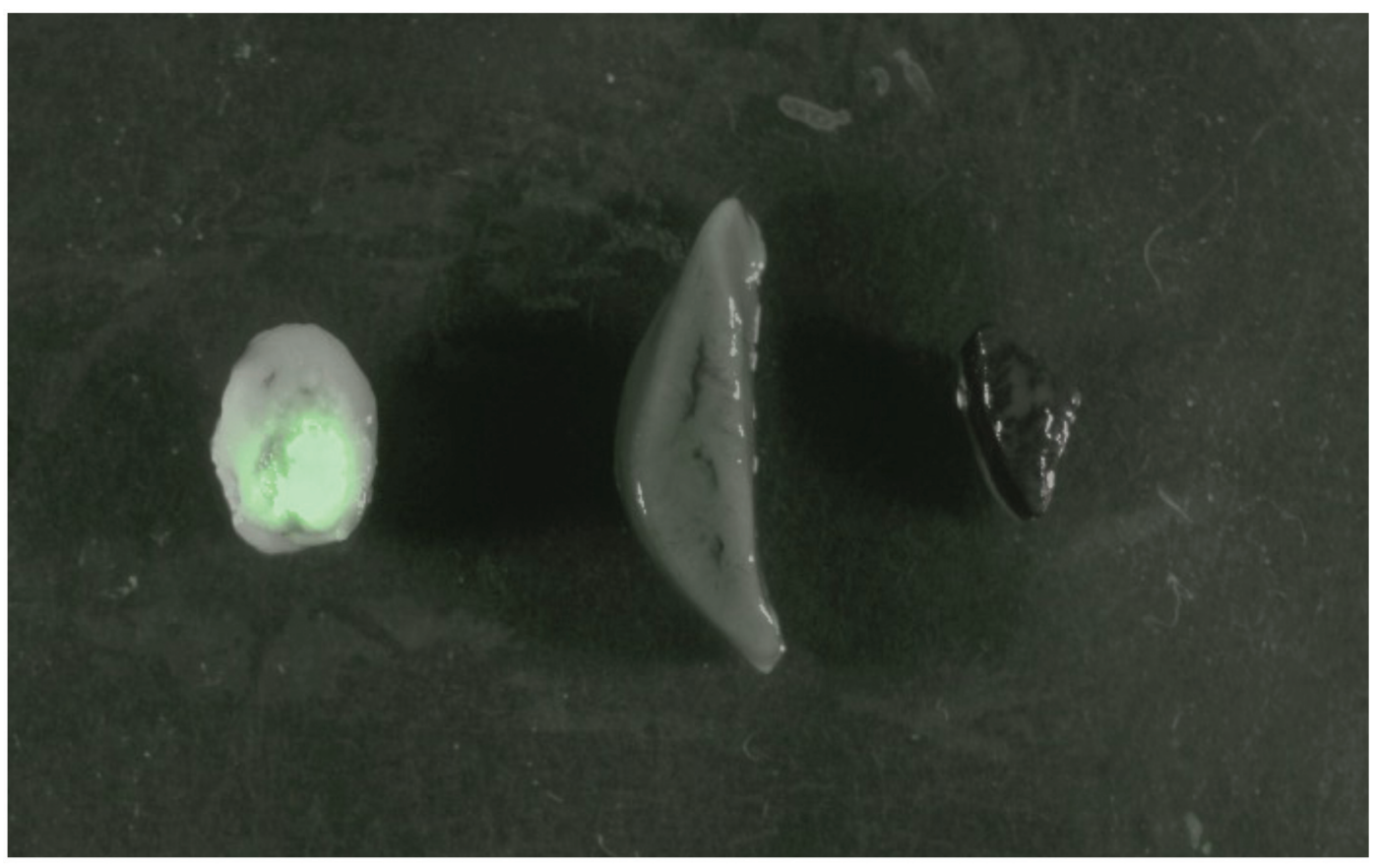

Tumor

Liver

Spleen

Figure 2. Tumor targeting by S. typhimurium A1-R-GFP. Selective tumor targeting of S. typhimurium A1-R-GFP to the triple-negative matrixproducing breast carcinoma (MPBC) PDOX. Imaging was performed with the UVP ChemStudio (Analytik, Jena, Germany). Representative images are shown.

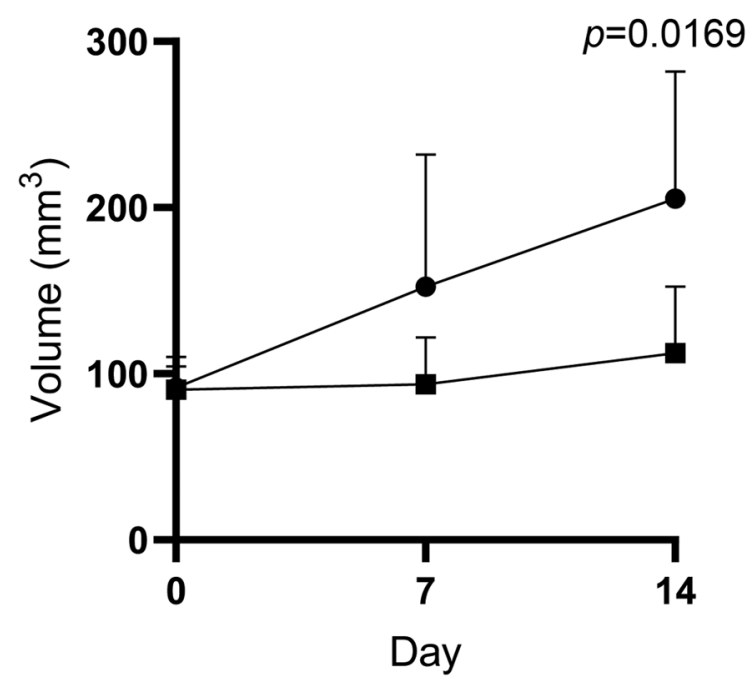

$\rightarrow$ Control

$\rightarrow$ S. typhimurium A1-R

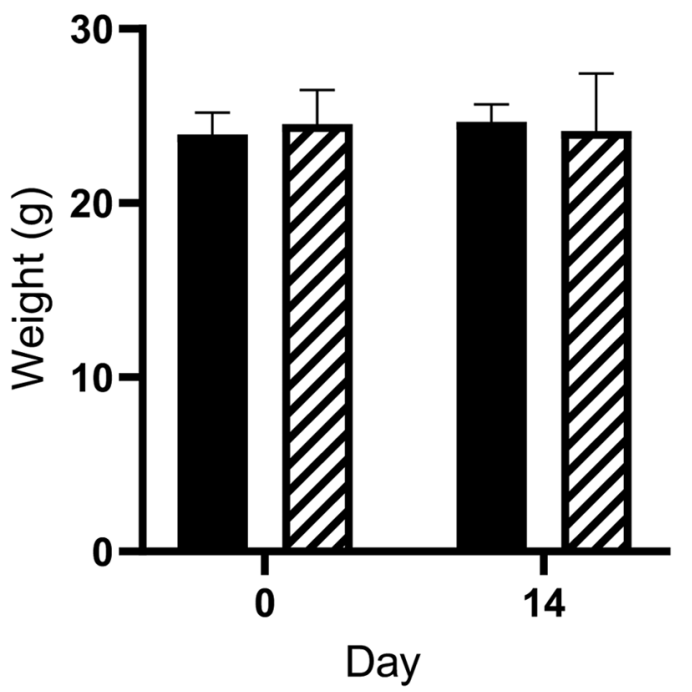

- Control

(20. S. typhimurium A1-R
Figure 3. Efficacy of $S$. typhimurium A1-R-GFP on the triple-negative matrix-producing breast carcinoma $(M P B C) P D O X$ nude mice. Tumors were measured at the indicated time points after the initiation of treatment. Control group $(n=6)$ vs. S. typhimurium A1-R-GFP-treated group $(n=7)$. Line graphs show the tumor volume at the indicated time points. Error bars represent the mean $\pm S D$.
Figure 4. Effect of S. typhimurium A1-R-GFP on mouse body weight in each group. Bar graphs show the bodyweight of mice at the indicated time points. No significant body weight differences were observed between the groups at each point. Control group (n=6) vs., $S$. typhimurium A1-R-GFP-treated group $(n=7)$, on day 0, on day 14 , $p=0.53,0.73$, respectively. 
the rich nutritional milieu of tumors, but it is severely restricted in normal tissue (12). Thus S. typhimurium A1-R can directly target tumors as well as serve as an anti-tumor immuno-stimulator. In a previous study, we showed that $S$. typhimurium A1-R enabled CD-8 T-cells to penetrate tumors (33). In the present study, S. typhimurium A1-R-GFP primarily localized and proliferated in the triple-negative MPBC tumor and S. typhimurium A1-R-GFP was undetectable in the liver and spleen. These results suggest the clinical potential of $S$. typhimurium A1-R for triple-negative MPBC.

\section{Conclusion}

S. typhimurium A1-R-GFP exquisitely targeted and arrested the growth of a triple-negative MPBC in a PDOX mouse model without apparent toxicity. The triple-negative MPBC PDOX model allows the development of precise, individualized, improved therapy for patients with this recalcitrant disease.

\section{Conflicts of Interest}

AntiCancer Inc. uses PDOX models for contract research. K.H., Y.A., M.Z., N.S., and R.M.H. are or were unsalaried associates of AntiCancer Inc. C.H. is an unsalaried associate of AntiCancer Japan. The Authors declare no competing financial interests.

\section{Authors' Contributions}

K.H. and R.M.H designed and performed experiments, analyzed data, and wrote the article; T.M. provided the tumor specimen; C.H. established the patient tumor specimens in nude mice; J.Y., Z.M., N.S., Y.A., and M.B. provided technical support and conceptual advice.: K.H., T.T., and R.M.H. wrote, reviewed, and/or revised the manuscript.

\section{Funding}

The present study was funded in part by The Robert M Hoffman Foundation For Cancer Research which had no other role in the study.

\section{Acknowledgements}

This paper is dedicated to the memory of A. R. Moossa, M.D., Sun Lee, M.D., Professor Li Jiaxi, and Masaki Kitajima, M.D.

\section{References}

1 Gibson GR, Qian D, Ku JK and Lai LL: Metaplastic breast cancer: clinical features and outcomes. Am Surg 71(9): 725-730, 2005. PMID: 16468506.

2 Kusafuka K, Muramatsu K, Kasami M, Kuriki K, Hirobe K, Hayashi I, Watanabe H, Hiraki Y, Shukunami C, Mochizuki T and Kameya T: Cartilaginous features in matrix-producing carcinoma of the breast: four cases report with histochemical and immunohistochemical analysis of matrix molecules. Mod Pathol 21(10): 1282-1292, 2008. PMID: 18622387. DOI: 10.1038/ modpathol.2008.120
3 Shimada K, Ishikawa T, Yamada A, Sugae S, Narui K, Shimizu D, Chishima T and Endo I: Matrix-producing carcinoma as an aggressive triple-negative breast cancer: Clinicopathological features and response to neoadjuvant chemotherapy. Anticancer Res 39(7): 3863-3869, 2019. PMID: 31262914. DOI: 10.21873/ anticanres. 13536

4 Fu XY, Besterman JM, Monosov A and Hoffman RM: Models of human metastatic colon cancer in nude mice orthotopically constructed by using histologically intact patient specimens. Proc Natl Acad Sci USA 88(20): 9345-9349, 1991. PMID: 1924398. DOI: $10.1073 /$ pnas.88.20.9345

5 Hoffman RM: Patient-derived orthotopic xenografts: better mimic of metastasis than subcutaneous xenografts. Nat Rev Cancer 15(8): 451-452, 2015. PMID: 26422835. DOI: $10.1038 / \mathrm{nrc} 3972$

6 Furukawa T, Kubota T, Watanabe M, Kitajima M and Hoffman RM: Orthotopic transplantation of histologically intact clinical specimens of stomach cancer to nude mice: correlation of metastatic sites in mouse and individual patient donors. Int $\mathbf{J}$ Cancer 53(4): 608-612, 1993. PMID: 8436434. DOI: 10.1002/ ijc. 2910530414

7 Hoffman RM: Orthotopic metastatic mouse models for anticancer drug discovery and evaluation: a bridge to the clinic. Invest New Drugs 17(4): 343-359, 1999. PMID: 10759402. DOI: $10.1023 / \mathrm{a}: 1006326203858$

8 Yamamoto J, Murata T, Tashiro Y, Higuchi T, Sugisawa N, Nishino H, Inubushi S, Sun YU, Lim H, Miyake K, Hongo A, Nomura T, Saitoh W, Moriya T, Tanino H, Hozumi C, Bouvet M, Singh SR, Endo I and Hoffman RM: A triple-negative matrix-producing breast carcinoma patient-derived orthotopic xenograft (PDOX) mouse model is sensitive to bevacizumab and vinorelbine, regressed by eribulin and resistant to olaparib. Anticancer Res 40(5): 2509-2514, 2020. PMID: 32366395. DOI: 10.21873/anticanres.14221

9 Lim HI, Yamamoto J, Inubushi S, Nishino H, Tashiro Y, Sugisawa N, Han Q, Sun YU, Choi HJ, Nam SJ, Kim MB, Lee JS, Hozumi C, Bouvet M, Singh SR and Hoffman RM: A single low dose of eribulin regressed a highly aggressive triple-negative breast cancer in a patient-derived orthotopic xenograft model. Anticancer Res 40(5): 2481-2485, 2020. PMID: 32366392. DOI: 10.21873/anticanres.14218

10 Zhao M, Yang M, Li XM, Jiang P, Baranov E, Li S, Xu M, Penman $S$ and Hoffman RM: Tumor-targeting bacterial therapy with amino acid auxotrophs of GFP-expressing Salmonella typhimurium. Proc Natl Acad Sci USA 102(3): 755-760, 2005. PMID: 15644448. DOI: 10.1073/pnas.0408422102

11 Zhao M, Yang M, Ma H, Li X, Tan X, Li S, Yang Z and Hoffman RM: Targeted therapy with a Salmonella typhimurium leucine-arginine auxotroph cures orthotopic human breast tumors in nude mice. Cancer Res 66(15): 7647-7652, 2006. PMID: 16885365. DOI: 10.1158/0008-5472.CAN-06-0716

12 Zhao M, Geller J, Ma H, Yang M, Penman S and Hoffman RM: Monotherapy with a tumor-targeting mutant of Salmonella typhimurium cures orthotopic metastatic mouse models of human prostate cancer. Proc Natl Acad Sci USA 104(24): 1017010174, 2007. PMID: 17548809. DOI: 10.1073/pnas.0703867104

13 Zhang Y, Tome Y, Suetsugu A, Zhang L, Zhang N, Hoffman RM and Zhao M: Determination of the optimal route of administration of Salmonella typhimurium A1-R to target breast cancer in nude mice. Anticancer Res 32(7): 2501-2508, 2012. PMID: 22753706. 
14 Zhang Y, Miwa S, Zhang N, Hoffman RM and Zhao M: Tumortargeting Salmonella typhimurium A1-R arrests growth of breastcancer brain metastasis. Oncotarget 6(5): 2615-2622, 2015. PMID: 25575815. DOI: 10.18632/oncotarget.2811

15 Uchugonova A, Zhao M, Zhang Y, Weinigel M, König K and Hoffman RM: Cancer-cell killing by engineered Salmonella imaged by multiphoton tomography in live mice. Anticancer Res 32(10): 4331-4337, 2012. PMID: 23060555.

16 Liu F, Zhang L, Hoffman RM and Zhao M: Vessel destruction by tumor-targeting Salmonella typhimurium A1-R is enhanced by high tumor vascularity. Cell Cycle 9(22): 4518-4524, 2010. PMID: 21135579. DOI: 10.4161/cc.9.22.13744

17 Nagakura C, Hayashi K, Zhao M, Yamauchi K, Yamamoto N, Tsuchiya H, Tomita K, Bouvet M and Hoffman RM: Efficacy of a genetically-modified Salmonella typhimurium in an orthotopic human pancreatic cancer in nude mice. Anticancer Res 29(6): 1873-1878, 2009. PMID: 19528442.

18 Yam C, Zhao M, Hayashi K, Ma H, Kishimoto H, McElroy M, Bouvet $\mathrm{M}$ and Hoffman RM: Monotherapy with a tumortargeting mutant of $S$. typhimurium inhibits liver metastasis in a mouse model of pancreatic cancer. J Surg Res 164(2): 248-255, 2010. PMID: 19766244. DOI: 10.1016/j.jss.2009.02.023

19 Hiroshima Y, Zhao M, Zhang Y, Maawy A, Hassanein MK, Uehara F, Miwa S, Yano S, Momiyama M, Suetsugu A, Chishima T, Tanaka K, Bouvet M, Endo I and Hoffman RM: Comparison of efficacy of Salmonella typhimurium A1-R and chemotherapy on stem-like and non-stem human pancreatic cancer cells. Cell Cycle 12(17): 2774-2780, 2013. PMID: 23966167. DOI: $10.4161 / \mathrm{cc} .25872$

20 Matsumoto Y, Miwa S, Zhang Y, Hiroshima Y, Yano S, Uehara F, Yamamoto M, Toneri M, Bouvet M, Matsubara H, Hoffman RM and Zhao M: Efficacy of tumor-targeting Salmonella typhimurium A1-R on nude mouse models of metastatic and disseminated human ovarian cancer. J Cell Biochem 115(11): 1996-2003, 2014. PMID: 24924355. DOI: 10.1002/jcb.24871

21 Matsumoto Y, Miwa S, Zhang Y, Zhao M, Yano S, Uehara F, Yamamoto M, Hiroshima Y, Toneri M, Bouvet M, Matsubara H, Tsuchiya $\mathrm{H}$ and Hoffman RM: Intraperitoneal administration of tumor-targeting Salmonella typhimurium A1-R inhibits disseminated human ovarian cancer and extends survival in nude mice. Oncotarget 6(13): 11369-11377, 2015. PMID: 25957417. DOI: $10.18632 /$ oncotarget.3607

22 Yano S, Zhang Y, Zhao M, Hiroshima Y, Miwa S, Uehara F, Kishimoto H, Tazawa H, Bouvet M, Fujiwara T and Hoffman RM: Tumor-targeting Salmonella typhimurium A1-R decoys quiescent cancer cells to cycle as visualized by FUCCI imaging and become sensitive to chemotherapy. Cell Cycle 13(24): 3958-3963, 2014. PMID: 25483077. DOI: 10.4161/15384101.2014.964115

23 Hiroshima Y, Zhang Y, Zhao M, Zhang N, Murakami T, Maawy A, Mii S, Uehara F, Yamamoto M, Miwa S, Yano S, Momiyama M, Mori R, Matsuyama R, Chishima T, Tanaka K, Ichikawa Y, Bouvet M, Endo I and Hoffman RM: Tumor-targeting Salmonella typhimurium A1-R in combination with trastuzumab eradicates HER-2-positive cervical cancer cells in patientderived mouse models. PLoS One 10(6): e0120358, 2015. PMID: 26047477. DOI: 10.1371/journal.pone.0120358

24 Murakami T, DeLong J, Eilber FC, Zhao M, Zhang Y, Zhang N, Singh A, Russell T, Deng S, Reynoso J, Quan C, Hiroshima Y, Matsuyama R, Chishima T, Tanaka K, Bouvet M, Chawla S, Endo I and Hoffman RM: Tumor-targeting Salmonella typhimurium A1-R in combination with doxorubicin eradicate soft tissue sarcoma in a patient-derived orthotopic xenograft (PDOX) model. Oncotarget 7(11): 12783-12790, 2016. PMID: 26859573. DOI: $10.18632 /$ oncotarget.7226

25 Hiroshima Y, Zhao M, Zhang Y, Zhang N, Maawy A, Murakami T, Mii S, Uehara F, Yamamoto M, Miwa S, Yano S, Momiyama M, Mori R, Matsuyama R, Chishima T, Tanaka K, Ichikawa Y, Bouvet M, Endo I and Hoffman RM: Tumor-targeting Salmonella typhimurium A1-R arrests a chemo-resistant patient soft-tissue sarcoma in nude mice. PLoS One 10(8): e0134324, 2015. PMID: 26237416. DOI: 10.1371/journal.pone.0134324

26 Kiyuna T, Murakami T, Tome Y, Kawaguchi K, Igarashi K, Zhang Y, Zhao M, Li Y, Bouvet M, Kanaya F, Singh A, Dry S, Eilber FC and Hoffman RM: High efficacy of tumor-targeting Salmonella typhimurium A1-R on a doxorubicin- and dactolisib-resistant follicular dendritic-cell sarcoma in a patient-derived orthotopic xenograft PDOX nude mouse model. Oncotarget 7(22): 3304633054, 2016. PMID: 27105519. DOI: 10.18632/oncotarget.8848

27 Yamamoto M, Zhao M, Hiroshima Y, Zhang Y, Shurell E, Eilber FC, Bouvet M, Noda M and Hoffman RM: Efficacy of tumortargeting Salmonella A1-R on a melanoma patient-derived orthotopic xenograft (PDOX) nude-mouse model. PLoS One 11(8): e0160882, 2016. PMID: 27500926. DOI: 10.1371/journal. pone. 0160882

28 Momiyama M, Zhao M, Kimura H, Tran B, Chishima T, Bouvet M, Endo I and Hoffman RM: Inhibition and eradication of human glioma with tumor-targeting Salmonella typhimurium in an orthotopic nude-mouse model. Cell Cycle 11(3): 628-632, 2012. PMID: 22274398. DOI: 10.4161/cc.11.3.19116

29 Wargotz ES and Norris HJ: Metaplastic carcinomas of the breast. I. Matrix-producing carcinoma. Hum Pathol 20(7): 628-635, 1989. PMID: 2544506. DOI: 10.1016/0046-8177(89)90149-4

30 Al Sayed AD, El Weshi AN, Tulbah AM, Rahal MM and Ezzat AA: Metaplastic carcinoma of the breast clinical presentation, treatment results and prognostic factors. Acta Oncol 45(2): 188195, 2006. PMID: 16546865. DOI: 10.1080/02841860500513235

31 Hennessy BT, Giordano S, Broglio K, Duan Z, Trent J, Buchholz TA, Babiera G, Hortobagyi GN and Valero V: Biphasic metaplastic sarcomatoid carcinoma of the breast. Ann Oncol 17(4): 605-613, 2006. PMID: 16469754. DOI: 10.1093/annonc/md1006

32 Forbes NS, Coffin RS, Deng L, Evgin L, Fiering S, Giacalone M, Gravekamp C, Gulley JL, Gunn H, Hoffman RM, Kaur B, Liu K, Lyerly HK, Marciscano AE, Moradian E, Ruppel S, Saltzman DA, Tattersall PJ, Thorne S, Vile RG, Zhang HH, Zhou S and McFadden G: White paper on microbial anti-cancer therapy and prevention. J Immunother Cancer 6(1): 78, 2018. PMID: 30081947. DOI: 10.1186/s40425-018-0381-3

33 Murakami T, Hiroshima Y, Zhang Y, Zhao M, Kiyuna T, Hwang HK, Miyake K, Homma Y, Mori R, Matsuyama R, Chishima T, Ichikawa Y, Tanaka K, Bouvet M, Endo I and Hoffman RM: Tumor-targeting Salmonella typhimurium A1-R promotes tumoricidal $\mathrm{CD}^{+}+\mathrm{T}$ cell tumor infiltration and arrests growth and metastasis in a syngeneic pancreatic-cancer orthotopic mouse model. J Cell Biochem 119(1): 634-639, 2018. PMID: 28628234. DOI: $10.1002 /$ jcb. 26224

Received August 1, 2021

Revised August 23, 2021

Accepted August 24, 2021 